\title{
Effect of Spraying Speed on Head Coverage of Winter Wheat with Fungicide, Occurrence of Fusarium Head Blight and Deoxynivalenol, Yield and Grain Quality
}

\author{
A. SREŠ ${ }^{1}$, S. TRDAN ${ }^{2}$, G. LESKOŠEK ${ }^{3}$, M. VIDRIH ${ }^{2}$ and F. VUČAJNK ${ }^{2 *}$ \\ ${ }^{1}$ Bayer d.o.o., Bayer CropScience, Bravničarjeva 13, SI-1000 Ljubljana, Slovenia \\ ${ }^{2}$ Chair of Phytomedicine, Agricultural Engineering, Crop Production, Pasture and Grassland Management, \\ Department of Agronomy, Biotechnical Faculty, University of Ljubljana, Jamnikarjeva 101, \\ SI-1111 Ljubljana, Slovenia \\ ${ }^{3}$ Slovenian Institute for Hop Research and Brewing, Cesta Žalskega tabora 2, SI-3310 Žalec, Slovenia
}

(Received 18 February 2014; Accepted 21 May 2014)

\begin{abstract}
The effect of spraying speed $(5,8.5$ or $12 \mathrm{~km} / \mathrm{h})$ on deposition quality of fungicide on a winter wheat head, yield, grain quality, occurrence of Fusarium head blight (FHB) and deoxynivalenol (DON) content in grains was investigated in 2011 and 2012. Asymmetric double flat fan air-injector nozzles were used in the trial at a spraying pressure of 5.0 bars. A prothiconazole + tebuconazole fungicide mixture was used for spraying. An increase of spraying speed significantly lowered coverage values at the front and rear parts of a wheat head. At all three spraying speeds, the rear part of a wheat head reached a better coverage value. The effect of spraying speed was significant in 2011, when the $5 \mathrm{~km} / \mathrm{h}$ spraying speed generated a significantly higher grain yield and a significantly higher thousand-grain weight in comparison with the other treatments. In both trial years, the lowest grain yield occurred on the unsprayed control. In 2011 and 2012, the latter also reached the lowest hectolitre weight and thousand-grain weight. In both trial years, the unsprayed control had a significantly higher DON content than the other treatments. In 2012, the DON content on the unsprayed control exceeded the allowed maximum level. The spraying speed did not affect the DON content in the grains. The effect of spraying speed was also noted in the FHB incidence. A significantly lower FHB incidence occurred at the 5 and $8.5 \mathrm{~km} / \mathrm{h}$ spraying speeds.
\end{abstract}

Keywords: coverage value, deoxynivalenol, Fusarium head blight, grain quality, nozzle, spraying speed, yield

\section{Introduction}

Fusarium head blight (FHB) is one of the most severe wheat diseases, which can be caused by various species of Fusarium genus (Mesterházy et al. 2003; Blandino et al. 2006). Various international research studies show that head coverage with fungicide spray mixture is less efficient and unequal on the front and rear parts of a head (McMullen et al. 1999b).

\footnotetext{
* Corresponding author; E-mail: filip.vucajnk@bf.uni-lj.si; Phone: +386 13203131; Fax: +386 14231088
} 
Halley et al. (1999) compared various spraying methods and concluded that the coverage value on the rear part of a wheat head does not usually exceed $10 \%$, while the front part normally reaches a $20 \%$ coverage value. Ruden et al. $(2005,2007)$ also stated that most nozzle types ensure better coverage of the front part of a head. Several authors determined that the front and rear parts of a head have better fungicide coverage when single backward-angled nozzles, symmetric double flat fan nozzles or as symmetric double flat fan nozzles are used (Miller et al. 2002; Parkin et al. 2006; Vajs et al. 2008; Knewitz and Koch 2010). Hooker et al. (2004) stated that both standard and new spraying technologies allow for a $10 \%$ coverage value on wheat heads. The Turbo FloodJet flooding flat fan nozzle was the only nozzle, the use of which resulted in a $30 \%$ coverage on both the front and the rear part of a wheat head. The use of standard nozzles resulted in better coverage of the front part of a wheat head, which ranged from 10 to 30\%, while the coverage of the rear part only reached $3-8 \%$. The spray deposition of fungicide on a wheat head was much less efficient when nozzles with a vertical spray jet were used.

The FHB lowers the yield and causes grains to become contaminated with mycotoxins, particularly deoxynivalenol (DON) (Groth et al. 2011; Miedaner 2012). In favourable conditions, FHB may lower the yield by up to $30 \%$. Such conditions lower the quality of wheat, which results in a lower thousand-grain weight and a higher percentage of fine, scabby and coloured grains. Various studies showed that FHB can be efficiently controlled by using the prothiconazole + tebuconazole fungicide mixture, which can reduce the DON content by 22-72\% (Homdork et al. 2000; Hart et al. 2001; McMullen et al. 2001). Miedaner (2012) stated that contamination can be reduced by $50-70 \%$, while the DON content in grains can be lowered by $50-80 \%$. The maximum level of the DON content in unprocessed cereal foodstuffs is $1,250 \mu \mathrm{g} / \mathrm{kg}$ of grains (Commission Regulation 2005). In addition, Miedaner (2012) stated that grains should not contain more than $5 \%$ of Fusarium damaged kernels (FDK). FDK are fine underdeveloped grains with blunt surface that are reddish in colour. With very susceptible cultivars, the mycotoxin content still exceeds the maximum level after the use of FHB control fungicides despite the significantly reduced level of FHB occurrence (Mesterházy et al. 2011). In the years with severe contaminations, it was not possible to reduce FDK to less than 5\%. In comparison with the standard nozzle, the use of Turbo FloodJet flooding flat fan nozzle resulted in a reduced level of FHB incidence and DON contamination.

The aim of the trial was to determine the effect of spraying speed while using an asymmetric double flat fan air-injector nozzle during wheat head spraying with a prothiconazole + tebuconazole fungicide mixture on fungicide deposition quality, yield, grain quality, DON content and FHB occurrence.

\section{Materials and Methods}

\section{Field trial}

The field trial was performed in the Biotechnical Faculty laboratory field in Ljubljana $\left(46^{\circ} 03^{\prime} \mathrm{N}, 14^{\circ} 31^{\prime} \mathrm{E}\right)$ (Slovenia, altitude: $298 \mathrm{~m}$ ). The soil on the trial plot was classified as 
heavy soil containing $30 \%$ of clay. The pre-crop on the trial field had been grain maize. In autumn, the trial plot had been ploughed with reversible plough. In the trial, Isengrain winter wheat cultivar, a moderately FHB susceptible cultivar and an awn wheat, was used. The breeder of Isengrain winter wheat cultivar is a French company S.A.S. Florimond Desprez. The trial base consisted of random blocks with three repetitions. At each block, three plots with different spraying speeds and an unsprayed control were randomly distributed. The unsprayed control was not head-sprayed with the FHB control fungicide. Blocks were $105 \mathrm{~m}$ long and $9 \mathrm{~m}$ wide. Individual trial plots were $35 \mathrm{~m}$ long and $9 \mathrm{~m}$ wide.

Three different spraying speeds were used for wheat head spraying: $5 \mathrm{~km} / \mathrm{h}, 8.5 \mathrm{~km} / \mathrm{h}$ and $12 \mathrm{~km} / \mathrm{h}$. At the $5 \mathrm{~km} / \mathrm{h}$ spraying speed, the volume application rate was $360 \mathrm{~L} / \mathrm{ha}$. At the $8.5 \mathrm{~km} / \mathrm{h}$ and $12 \mathrm{~km} / \mathrm{h}$ speeds, it was $215 \mathrm{~L} / \mathrm{ha}$ and $150 \mathrm{~L} / \mathrm{ha}$, respectively. TurboDrop HighSpeed 11003 asymmetric double air-injector flat fan nozzles were used in the trial. The first spray jet was angled forward at $10^{\circ}$ to the perpendicular and the second one backwards at $50^{\circ}$ to the perpendicular. At all spraying speeds, the same 5.0 bar spraying pressure and $1.55 \mathrm{~L} / \mathrm{min}$ nozzle flow rate were used. At the beginning of anthesis, i.e. growth stage (GS) 60 according to the Zadoks scale, Prosaro fungicide (prothiconazole $125 \mathrm{~g} / \mathrm{L}+$ tebuconazole $125 \mathrm{~g} / \mathrm{L}$ ) was used for spraying at a $1 \mathrm{~L} / \mathrm{ha}$ application rate. The weather conditions favoured the development of FHB. In May 2011, the precipitation was $98 \mathrm{~mm}$, while, in May 2012, there were $124 \mathrm{~mm}$ of rainfall. An AGS $600 \mathrm{EN}$ tractor mounted sprayer (Agromehanika, d.d., Slovenia) was used in the trial. Before the wheat head spraying, 5 plants were randomly chosen from each plot and water-sensitive paper was attached on the front and rear parts of their heads. The front part of a wheat head is the part facing the course of spraying. The rear part of a wheat head, in contrast, is the part left behind during the spraying. In addition to these 5 plants, 5 poles were randomly erected at a $90^{\circ}$ angle on individual trial plots. Water-sensitive paper was attached to the front and rear parts of each pole. The droplet impression measurements on water-sensitive paper were performed with Optomax V. Image Analyser, a measuring system for imaging and image analysis. The coverage value was analysed according to different spraying speeds during wheat head spraying. All the other agri-technical work in the trial field (soil cultivation, sowing, spraying and fertilisation) was performed in accordance with good agricultural practice.

Three weeks after the wheat head spraying, 5 measuring points $(0.5 \times 0.5 \mathrm{~m}$, i.e. a $0.25 \mathrm{~m}^{2}$ area) were randomly chosen on each trial plot. The number of heads contaminated with FHB and the number of all the plants were determined for each measuring point. Based on these data, the FHB incidence was calculated. The wheat was harvested with a plot harvester with a $1.5 \mathrm{~m}$ working width. On each trial plot, a $45 \mathrm{~m}^{2}$ area was harvested. The grains gathered on trial plots were weighed with digital scales with a measuring range of up to $60 \mathrm{~kg}$. A digital moisture meter was used to measure moisture in the grains at the harvest. Two grain moisture measurements were performed on each sample. Based on these data, the grain yield with a $14 \%$ moisture content was calculated. On each trial plot, 2 grain samples were gathered to determine the hectolitre grain weight with a Shopper chondrometer. The thousand-grain weight was determined for each trial plot. The grains were separated into groups of 100 and weighed with laboratory digital scales. On each trial 
plot, 8 measurements of the thousand-grain weight were performed. FHB grains underwent laboratory analysis on a technical agar. Petri dishes with grains were placed in an incubator set at $20^{\circ} \mathrm{C}$, where they were left in the light for 5 days. Five days later, the damaged kernels were counted and FDK was calculated. On each trial plot, 4 measurements were performed. 300 random wheat heads were collected on individual trial plots before the harvest. The DON content in wheat grains was determined with a ROSA ${ }^{\circledR}$ DON Quantitative Flow Chart Test.

\section{Statistical analysis}

Statistical treatment was performed according to the procedures applicable to random blocks. First, homogeneity of variance was determined. As and when required, the data were transformed. The percentage data were transformed using the 'asin (sqrt/100)' function. An analysis of variance (ANOVA) and Duncan's Multiple Range Test were performed. Statistical differences were significant if $P<0.05$ and differences among the treatments were marked with different letters. The data were shown as means with standard errors. If more measurements were made for each treatment, the statistical analysis was performed according to the procedures applicable to random blocks with repetitions within the trial units. All statistical analyses were performed with the Statgraphics Centurion XVI computer software (StatPoint Technologies, Inc.).

\section{Results}

\section{Coverage value}

In 2011, a significantly higher coverage value occurred on the front part of a wheat head at the 5 and $8.5 \mathrm{~km} / \mathrm{h}$ spraying speeds in comparison with the $12 \mathrm{~km} / \mathrm{h}$ spraying speed. In 2012, significantly the highest coverage value occurred on the front part of a head at the $5 \mathrm{~km} / \mathrm{h}$ spraying speed, followed by the $8.5 \mathrm{~km} / \mathrm{h}$ spraying speed, while significantly the lowest coverage value occurred at the $12 \mathrm{~km} / \mathrm{h}$ speed (Table 1). In both trial years, significantly the highest coverage value on the front part of a pole occurred at the $5 \mathrm{~km} / \mathrm{h}$ spraying speed, it was slightly lower at the $8.5 \mathrm{~km} / \mathrm{h}$ spraying speed and the lowest at the $12 \mathrm{~km} / \mathrm{h}$ spraying speed. Significantly the highest coverage value on the rear part of a head occurred at the $5 \mathrm{~km} / \mathrm{h}$ spraying speed in both trial years. In 2011, the coverage of the rear part of a head was significantly the lowest at $12 \mathrm{~km} / \mathrm{h}$, while in 2012 no statistically significant differences were found in the coverage value at $8.5 \mathrm{~km} / \mathrm{h}$ and at $12 \mathrm{~km} / \mathrm{h}$. In both trial years, significantly the highest coverage value on the rear part of a pole occurred at the $5 \mathrm{~km} / \mathrm{h}$ spraying speed. In 2011, the coverage was significantly the lowest at $12 \mathrm{~km} / \mathrm{h}$, while in 2012 no statistically significant differences were found in the coverage value at $8.5 \mathrm{~km} / \mathrm{h}$ and at $12 \mathrm{~km} / \mathrm{h}$.

Yield, hectolitre weight and thousand-grain weight

In both trial years, the unsprayed control had significantly the lowest grain yield with a $14 \%$ moisture content (Table 2). In 2011, a significantly higher yield occurred at the 5 and 
Table 1. Coverage value on the front and the rear part of a head or a pole at different spraying speeds in wheat head FHB control spraying $(\%)$. The data are represented as means \pm standard errors

\begin{tabular}{|c|c|c|c|c|c|}
\hline \multirow{3}{*}{ Year } & \multirow{3}{*}{$\begin{array}{c}\text { Spraying } \\
\text { speed }(\mathrm{km} / \mathrm{h})\end{array}$} & \multicolumn{4}{|c|}{ Coverage value (\%) } \\
\hline & & \multicolumn{2}{|c|}{ Head } & \multicolumn{2}{|c|}{ Pole } \\
\hline & & Front & Rear & Front & Rear \\
\hline \multirow{3}{*}{2011} & 5 & $16.1 \pm 2.03^{\mathrm{al}}$ & $40.2 \pm 2.10^{\mathrm{a}}$ & $13.8 \pm 1.01^{\mathrm{a}}$ & $29.5 \pm 1.63^{\mathrm{a}}$ \\
\hline & 8.5 & $15.0 \pm 2.36^{\mathrm{a}}$ & $26.6 \pm 1.80^{\mathrm{b}}$ & $10.9 \pm 0.73^{b}$ & $24.2 \pm 1.18^{\mathrm{b}}$ \\
\hline & 12 & $10.5 \pm 1.24^{\mathrm{b}}$ & $17.2 \pm 2.23^{\mathrm{c}}$ & $7.9 \pm 0.80^{\mathrm{c}}$ & $8.4 \pm 0.62^{\mathrm{c}}$ \\
\hline \multirow{3}{*}{2012} & 5 & $26.6 \pm 3.13^{\mathrm{a}}$ & $33.5 \pm 2.96^{\mathrm{a}}$ & $9.8 \pm 0.62^{\mathrm{a}}$ & $30.1 \pm 1.53^{\mathrm{a}}$ \\
\hline & 8.5 & $17.2 \pm 1.86^{\mathrm{b}}$ & $14.3 \pm 1.54^{b}$ & $7.8 \pm 0.58^{\mathrm{b}}$ & $11.3 \pm 0.81^{\mathrm{b}}$ \\
\hline & 12 & $8.5 \pm 0.74^{\mathrm{c}}$ & $14.1 \pm 1.01^{\mathrm{b}}$ & $4.5 \pm 0.35^{\mathrm{c}}$ & $10.0 \pm 0.70^{\mathrm{b}}$ \\
\hline
\end{tabular}

${ }^{1}$ The means within each column in the same year followed by different letters are significantly different at the 0.05 level according to Duncan's test.

$8.5 \mathrm{~km} / \mathrm{h}$ spraying speeds in comparison with the $12 \mathrm{~km} / \mathrm{h}$ spraying speed and the unsprayed control. In 2012, no statistically significant differences were found in the grain yield at different spraying speeds. In 2011, the yields of grain ranged from $9,115 \mathrm{~kg} / \mathrm{ha}$ (unsprayed control) to $10,073 \mathrm{~kg} / \mathrm{ha}(5 \mathrm{~km} / \mathrm{h})$. In 2012 , they ranged from $4,680 \mathrm{~kg} / \mathrm{ha}$ (unsprayed control) to $6,645 \mathrm{~kg} / \mathrm{ha}(12 \mathrm{~km} / \mathrm{h})$. In 2011 , no statistically significant differences were found in the hectolitre weight among the treatments. The hectolitre weight was approximately $77 \mathrm{~kg} / \mathrm{hl}$. In 2012, a significantly lower hectolitre grain weight occurred on the unsprayed control in comparison with the other spraying speeds. In 2012, the hectolitre weight (approximately $74 \mathrm{~kg} / \mathrm{hl}$ ) was lower than in 2011 (approximately $77 \mathrm{~kg} / \mathrm{hl}$ ). In comparison with the hectolitre weight, the differences among various treatments were even more prominent when comparing the thousand-grain weight. In 2011, the thousand-grain weight was significantly higher at the $5 \mathrm{~km} / \mathrm{h}$ spraying speed than with the other treatments. At $5 \mathrm{~km} / \mathrm{h}$, it reached $42.2 \mathrm{~g}$, in other treatments approximately $40 \mathrm{~g}$.

Table 2. Grain yield with a $14 \%$ moisture content $(\mathrm{kg} / \mathrm{ha})$, hectolitre grain weight $(\mathrm{kg} / 100 \mathrm{~L})$ and thousand-grain weight (g/1,000 grains) at different spraying speeds in wheat head FHB control spraying. The data are represented as means \pm standard errors

\begin{tabular}{ccccc}
\hline Year & $\begin{array}{c}\text { Spraying speed } \\
(\mathrm{km} / \mathrm{h})\end{array}$ & $\begin{array}{c}\text { Yield }-14 \% \mathrm{~m} . \mathrm{c} . \\
(\mathrm{kg} / \mathrm{ha})\end{array}$ & $\begin{array}{c}\text { Hectolitre weight } \\
(\mathrm{kg} / \mathrm{hl})\end{array}$ & $\begin{array}{c}\text { Thousand g. w. } \\
(\mathrm{g} / 1,000 \text { grains })\end{array}$ \\
\hline 2011 & unsprayed control & $9,115 \pm 80.67^{\mathrm{al}}$ & $77.0 \pm 0.25^{\mathrm{a}}$ & $39.6 \pm 0.51^{\mathrm{a}}$ \\
& 5 & $10,073 \pm 118.94^{\mathrm{b}}$ & $77.2 \pm 0.24^{\mathrm{a}}$ & $42.2 \pm 0.37^{\mathrm{b}}$ \\
& 8.5 & $9,906 \pm 16.12^{\mathrm{b}}$ & $76.7 \pm 0.18^{\mathrm{a}}$ & $39.6 \pm 0.29^{\mathrm{a}}$ \\
& 12 & $9,633 \pm 94.51^{\mathrm{c}}$ & $77.0 \pm 0.40^{\mathrm{a}}$ & $40.4 \pm 0.71^{\mathrm{a}}$ \\
\hline 2012 & unsprayed control & $4,680 \pm 34.27^{\mathrm{a}}$ & $69.3 \pm 1.24^{\mathrm{a}}$ & $30.3 \pm 0.67^{\mathrm{a}}$ \\
& 5 & $6,566 \pm 115.56^{\mathrm{b}}$ & $74.1 \pm 0.79^{\mathrm{b}}$ & $37.3 \pm 0.85^{\mathrm{b}}$ \\
& 8.5 & $6,645 \pm 86.56^{\mathrm{b}}$ & $74.3 \pm 0.51^{\mathrm{b}}$ & $36.3 \pm 0.34^{\mathrm{b}}$ \\
& 12 & $6,631 \pm 41.39^{\mathrm{b}}$ & $73.8 \pm 0.50^{\mathrm{b}}$ & $36.8 \pm 0.55^{\mathrm{b}}$ \\
\hline
\end{tabular}

${ }^{1}$ The means within each column in the same year followed by different letters are significantly different at the 0.05 level according to Duncan's test. 
In 2012, the differences in the thousand-grain weight were more pronounced. The unsprayed control, in particular, had a significantly lower thousand-grain weight than the other treatments. It was as low as $30.3 \mathrm{~g}$, while, in the other treatments, it ranged from $36.3 \mathrm{~g}$ to $37.3 \mathrm{~g}$. In both trial years, there was a minor occurrence of Septoria nodorum (Berk.) fungus. Three weeks after the wheat head spraying, less than $5 \%$ of the flag leaf area was contaminated. This result is below the damage threshold according to the statements by Eyal et al. (1987). This plant disease thus had no effect on yield and thousand-grain weight. The disease was assessed according to the EPPO standards. Other plant diseases were not present.

\section{DON content, FHB incidence and FDK}

In both trial years, the DON content in wheat grains on the unsprayed control was significantly higher than in the other treatments (Table 3). Nevertheless, the DON content $(609 \mu \mathrm{g} / \mathrm{kg})$ on the unsprayed control in 2011 did not exceed the maximum level of $1,250 \mu \mathrm{g} / \mathrm{kg}$ of grains. In the same year, the DON content in the grains was below $200 \mu \mathrm{g} / \mathrm{kg}$ at all three spraying speeds. In 2012, the grains on the unsprayed control had a $2,737 \mu \mathrm{g} / \mathrm{kg}$ DON content. This value exceeds the allowed maximum level of $1,250 \mu \mathrm{g} / \mathrm{kg}$. Similarly than in 2011 , low DON content was reached at all three speeds during the FHB control spraying. In comparison with the unsprayed control, the DON content at different spraying speeds decreased on average by $70 \%$ and $94 \%$ in 2011 and 2012 , respectively. In both trial years, a significantly higher FHB incidence occurred on the unsprayed control, i.e. $3.4 \%$ in 2011 and $25.3 \%$ in 2012 (Table 3). Furthermore, in these years, a significantly higher FHB incidence occurred at the $12 \mathrm{~km} / \mathrm{h}$ spraying speed than at the $5 \mathrm{~km} / \mathrm{h}$ and $8 \mathrm{~km} / \mathrm{h}$ speeds. In general, there was a substantially higher FHB incidence in all the treatments in 2012. It ranged from $7.5 \%$ to $25.3 \%$, while in 2011 in only ranged from 0.1 to $3.4 \%$. FDK analysis was also performed. In both trial years, significantly higher FDK occurred on the unsprayed control in comparison with the different spraying speeds. There were, however, large differences between the two years. In 2011, 2.5\% of

Table 3. DON content in wheat grains $(\mu \mathrm{g} / \mathrm{kg})$, FHB incidence (\%) and FDK (\%) at different spraying speeds in wheat head FHB control spraying. The data are represented as means \pm standard errors

\begin{tabular}{ccccc}
\hline Year & $\begin{array}{c}\text { Spraying speed } \\
(\mathrm{km} / \mathrm{h})\end{array}$ & $\begin{array}{c}\text { DON content } \\
(\mu \mathrm{g} / \mathrm{kg} \text { of grains })\end{array}$ & $\begin{array}{c}\text { FHB incidence } \\
(\%)\end{array}$ & $\begin{array}{c}\text { FDK } \\
(\%)\end{array}$ \\
\hline 2011 & unsprayed control & $609 \pm 61.23^{\mathrm{a}}$ & $3.4 \pm 0.57^{\mathrm{a}}$ & $2.5 \pm 0.50^{\mathrm{a}}$ \\
& 5 & $174 \pm 11.15^{\mathrm{b}}$ & $0.1 \pm 0.13^{\mathrm{b}}$ & $0.7 \pm 0.38^{\mathrm{b}}$ \\
& 8.5 & $172 \pm 27.37^{\mathrm{b}}$ & $0.5 \pm 0.20^{\mathrm{b}}$ & $0.5 \pm 0.26^{\mathrm{b}}$ \\
& 12 & $199 \pm 19.64^{\mathrm{b}}$ & $1.7 \pm 0.20^{\mathrm{c}}$ & $0.5 \pm 0.36^{\mathrm{b}}$ \\
\hline 2012 & unsprayed control & $2,737 \pm 142.07^{\mathrm{a}}$ & $25.3 \pm 1.61^{\mathrm{a}}$ & $12.8 \pm 1.96^{\mathrm{a}}$ \\
& 5 & $145 \pm 35.15^{\mathrm{b}}$ & $7.5 \pm 0.38^{\mathrm{b}}$ & $2.8 \pm 1.00^{\mathrm{b}}$ \\
& 12 & $166 \pm 17.29^{\mathrm{b}}$ & $8.3 \pm 0.48^{\mathrm{b}}$ & $3.2 \pm 1.06^{\mathrm{b}}$ \\
& $196 \pm 28.84^{\mathrm{b}}$ & $10.7 \pm 0.70^{\mathrm{c}}$ & $3.8 \pm 1.06^{\mathrm{b}}$ \\
\hline
\end{tabular}

${ }^{1}$ The means within each column in the same year followed by different letters are significantly different at the 0.05 level according to Duncan's test. 
grains were contaminated on the unsprayed control, whereas a year later this value increased to $12.8 \%$. In 2011, all the treatments had a low FDK value (0.5\%-2.5\%). In 2012, the FDK value was high $(2.8 \%-12.8 \%)$.

\section{Discussion}

\section{Coverage value}

The coverage value results show that an increase of spraying speed lowers the coverage of the front and rear parts of a wheat head when an asymmetric double flat fan air-injector nozzle is used. These results are, furthermore, linked to a lower volume application rate at higher spraying speeds. At $5 \mathrm{~km} / \mathrm{h}$, the volume application rate amounted to $360 \mathrm{~L} / \mathrm{ha}$. At $8.5 \mathrm{~km} / \mathrm{h}$ and $12 \mathrm{~km} / \mathrm{h}$, it was $215 \mathrm{~L} / \mathrm{ha}$ and $150 \mathrm{~L} / \mathrm{ha}$, respectively. At all three spraying speeds, the spraying pressure of 5.0 bars was used. In general, the rear part of a wheat head had better coverage than its front part regardless of the spraying speed chosen in the trial, which was against our expectations.

Our results are not directly comparable with the findings of Halley et al. (1999) who determined that the rear part and the front part of a wheat head reach a $10 \%$ and $20 \%$ coverage, respectively. In their trial, a different nozzle type was used and the spraying speed differed from the ones used in our trial. The findings of Hooker et al. $(2004,2005)$ also do not agree with our own, as, in our trial, the coverage of the rear part of a wheat head exceeded the $10 \%$ value stated by them. Hooker et al. $(2004,2005)$ determined that a $30 \%$ coverage of the front and the rear part of a wheat head can be reached with the use of a Turbo FloodJet flooding flat fan nozzle at the $10 \mathrm{~km} / \mathrm{h}$ and $19 \mathrm{~km} / \mathrm{h}$ spraying speeds. In our trial, an approximately $30 \%$ coverage was reached at the $5 \mathrm{~km} / \mathrm{h}$ spraying speed in 2012 , with a $26.6 \%$ coverage of the front part of a head and a $33.5 \%$ coverage of its rear part. We did, however, use asymmetric double flat fan air-injector nozzles.

At the $8.5 \mathrm{~km} / \mathrm{h}$ and $12 \mathrm{~km} / \mathrm{h}$ spraying speeds, the coverage value was substantially lower. In our trial, this result was due to a lower volume application rate at the spraying speeds of $8.5 \mathrm{~km} / \mathrm{h}(215 \mathrm{~L} / \mathrm{ha})$ and $12 \mathrm{~km} / \mathrm{h}(150 \mathrm{~L} / \mathrm{ha})$ in comparison with $5 \mathrm{~km} / \mathrm{h}$ (360 L/ha). Our results, thus, do not agree with the findings of Hooker et al. $(2004,2005)$, who stated that spraying speed does not significantly affect the wheat head coverage. In their trial, the volume application rate at both spraying speeds remained the same, while in our trial it differed according to the spraying speed. They gained the best results while using nozzles with the most gentle spray angle to the horizontal on both the front and the rear part of a wheat head. In our trial, the coverage value on the rear part of a wheat head ranged from $14.1 \%$ (at $12 \mathrm{~km} / \mathrm{h}$ in 2012 ) to $40.2 \%$ (at $5 \mathrm{~km} / \mathrm{h}$ in 2011 ).

The coverage value on the front part, in contrast, ranged from $8.5 \%$ (at $12 \mathrm{~km} / \mathrm{h}$ in 2012 ) to $26.6 \%$ (at $5 \mathrm{~km} / \mathrm{h}$ in 2012). Similar occurred with the right-angled poles. We believe that the $10^{\circ}$ forward angle to the perpendicular of the spraying pattern is not sufficiently wide for the droplets to efficiently coat the front part of a wheat head. We presume that this angle should be $30^{\circ}$ or more. In both trial years, the coverage on the front and rear 
parts of the poles placed at an exactly $90^{\circ}$ angle to the ground was lower than on the front and rear parts of the heads.

It is presumed that the coverage was worse since poles are of a different shape and size than wheat heads. Furthermore, wheat heads never stand at an exact right angle to the ground. With Ruden et al. $(2005,2007)$, the use of different nozzle types in the trial resulted in better coverage of the front part of a wheat head in comparison with the rear part of a head. Our trial, in contrast, showed reverse results. Despite the assumption that the use of single nozzles does result in better coverage of the front part of a wheat head, the use of asymmetric double flat fan nozzles, in contrast, reaches better coverage of the rear part of a wheat head, as was proven in our trial. Our results partially agree with the results of McMullen et al. (1999a), whose coverage in the trial was 2 times better when a double volume application rate was applied. In our trial, the $5 \mathrm{~km} / \mathrm{h}$ spraying speed required a 2.4 times higher volume application rate than the $12 \mathrm{~km} / \mathrm{h}$ spraying speed. Furthermore, the coverage on both the front and the rear part of a wheat head at $5 \mathrm{~km} / \mathrm{h}$ was, in most of the treatments, two times higher than at $12 \mathrm{~km} / \mathrm{h}$. Our results agree with the findings of Derksen et al. (2012), who stated that higher volume application rates generate better coverage of wheat heads with a fungicide spray deposit. If volume application rate at all three spraying speeds in our trial had remained the same, the coverage value of the front and rear parts of a wheat head would have presumably also been higher at $8.5 \mathrm{~km} / \mathrm{h}$ and $12 \mathrm{~km} / \mathrm{h}$.

\section{Yield, hectolitre weight and thousand-grain weight}

In 2012, the difference among the yields gained on the unsprayed control and with other spraying speeds was almost 2,000 kg/ha (approximately $30 \%$ less), while in 2011 it was only $1,000 \mathrm{~kg} / \mathrm{ha}$ (approximately $9 \%$ less). The results agree with a statement of Miedaner (2012) that, in the years with high FHB infection, the yield on unsprayed plots can be up to $30 \%$ lower. In our trial, this occurred in 2012. It should be noted that yields in 2012 (from 9,115 to $10,073 \mathrm{~kg} / \mathrm{ha}$ ) were substantially higher than in 2011 (from 4,680 to $6,645 \mathrm{~kg} / \mathrm{ha}$ ). In 2011, a significantly higher grain yield occurred at the 5 and $8.5 \mathrm{~km} / \mathrm{h}$ spraying speeds when compared with the $12 \mathrm{~km} / \mathrm{h}$ spraying speed and the unsprayed control. By comparing these results to the coverage value results on the front and rear parts of a wheat head, it is possible to indicate that better head coverage with a fungicide spray deposit results in a higher grain yield. An increase in the spraying speed lowers the coverage value, which can, furthermore, cause the occurrence of a lower grain yield. It is presumed that, in 2012, considerably smaller grain yields that occurred in all the treatments were due to high FHB occurrence. In 2012, abundant precipitation was characteristic for the April-July period. This affected the development of wheat diseases. It also rained during the wheat anthesis.

The results show a possible considerable decrease in hectolitre grain weight in years with high FHB occurrence. This occurred on the unsprayed control in 2012. It is presumed that high FHB occurrence on the unsprayed control resulted in a higher percentage of fine scabby grains, which, in turn, lowered the hectolitre weight. Better weather conditions for wheat growth and development and less severe FHB occurrence in 2011 resulted in a much higher hectolitre weight in comparison with 2012. Spraying speed did not affect the hectolitre weight of the grains. 
Thousand-grain weight is directly linked to grain yield, which was demonstrated in both trial years. In 2011, the thousand-grain weight at the $5 \mathrm{~km} / \mathrm{h}$ spraying speed was significantly higher than in the other treatments. This result is presumably linked to very good wheat head coverage with a fungicide spray deposit at this spraying speed, which allows for better fungicide efficacy. Similar could be stated for the grain yield at the $5 \mathrm{~km} / \mathrm{h}$ spraying speed in 2011. It is interesting to note that, in 2011, the thousand-grain weight on the unsprayed control was not lower than at the 8.5 and $12 \mathrm{~km} / \mathrm{h}$ spraying speeds. We presume that, during that year, the FHB development was not as high and did not affect the decrease of the thousand-grain weight in the above-mentioned treatments. In 2012, the unsprayed control had substantially lower thousand-grain weight ( $30.3 \mathrm{~g}$ ) in comparison with the other treatments (from 36.3 to $37.3 \mathrm{~g}$ ). We presume that this result stems from higher FHB occurrence and high percentages of FDK that significantly contributed to the decrease in the thousand-grain weight and, subsequently, also the yield. Furthermore, lower thousand-grain weight and, consequently, lower yields in all the treatments in 2012 in comparison with 2011 were also a result of adverse weather conditions for wheat growth and development. The yield and grain analyses results confirm the findings of Miedaner (2012), who claimed that favourable conditions for the occurrence of FHB may lower the yield by up to $30 \%$, reduce the thousand-grain weight and increase the percentage of fine, scabby and coloured grains. Our results agree with the findings of Jones (2000), who stated that wheat head spraying against FHB reduces FHB development and FDK, while at the same time increasing the thousand-grain weight and grain yield.

\section{DON content, FHB incidence and FDK}

The decrease of the DON content on the sprayed plots in comparison with the unsprayed control even exceeded the findings of Miedaner (2012), who claimed that azole fungicides reduce the DON content in the grains by $50-80 \%$. In other researches, many other authors stated a $22-72 \%$ reduction of the DON content, while using the prothiconazole + tebuconazole fungicide mixture (Homdork et al. 2000; Hart et al. 2001; McMullen et al. 2001; Lechoczki-Krsjak et al. 2008). The results of our trial showed an even greater decrease of the DON content. On the basis of our results we are able to claim that different spraying speeds do not significantly affect the DON content. The results of the DON content decrease that we gained are comparable with Blandino et al. (2012), who reached a $97 \%$ decrease on the unsprayed control but, in contrast, studied other factors in the trial. Miedaner (2012) stated that a DON content on an unsprayed plot which exceeds $2,000 \mu \mathrm{g} / \mathrm{kg}$ of grains cannot be lowered under the maximum level of $1,250 \mu \mathrm{g} / \mathrm{kg}$ even with the use of a suitable fungicide. Our results do not confirm his statement. In 2012, the unsprayed control had a DON content of $2,737 \mu \mathrm{g} / \mathrm{kg}$ of grains, while plots sprayed at different spraying speeds reached values between 145 and $200 \mu \mathrm{g} / \mathrm{kg}$ of grains. Mesterházy et al. (2011), in contrast, stated that the use of fungicides in FHB control is inefficient with natural contaminations where the DON content exceeds $10,000 \mu \mathrm{g} / \mathrm{kg}$. If the DON content with natural contaminations is lower than $10,000 \mu \mathrm{g} / \mathrm{kg}$, the use of fungicides can lower it under the maximum level of $1,250 \mu \mathrm{g} / \mathrm{kg}$. Our trial did not consist of such high values, which hinders the direct comparison with the above-stated finding. 
High FHB incidence on the unsprayed control in 2012 indicated high FHB occurrence which resulted in a higher DON content on the unsprayed control and, particularly, in a lower yield and poorer quality of grains in all the treatments. In both trial years, the results showed higher FHB incidence at the $12 \mathrm{~km} / \mathrm{h}$ spraying speed in comparison with the other two spraying speeds. It is presumed that this result was due to worse coverage of the front and rear parts of a wheat head with a fungicide spray deposit at the $12 \mathrm{~km} / \mathrm{h}$ spraying speed. By linking the DON content results with the FHB incidence we were able to determine that the DON content can be low even at high FHB incidence. This result occurred in 2012, on plots sprayed at different spraying speeds.

By summing up the FDK results on the agar, it is possible to determine that sprayed plots have a very low DON content, despite a higher FHB incidence and a very high percentage of FDK that occurred in 2012. On the technical agar, $12.8 \%$ of grains of the unsprayed control were contaminated. This result reflects a strong FHB development in 2012. At $5,8.5$ and $12 \mathrm{~km} / \mathrm{h}$ spraying speeds, the FDK ranged between $2.8(5 \mathrm{~km} / \mathrm{h})$ and $3.8 \%(12 \mathrm{~km} / \mathrm{h})$, which is considerably less in comparison with the $12.8 \%$ of the unsprayed control. Due to the use of FHB control fungicide, the FDK values on the plots where different spraying speeds had been applied were considerably lower than on the unsprayed control. In general, all treatments in 2012 included higher FDK values than in 2011. This result reflects more favourable conditions for the FHB development in 2012. Miedaner (2012) stated that grains should not contain more than 5\% of FDK. If the percentage of FDK is lower than $1 \%$, the DON content in the grains will not exceed $500 \mu \mathrm{g} / \mathrm{kg}$. If the percentage of FDK is between 2 and $5 \%$, the DON content will range between 1,200 and $3,000 \mu \mathrm{g} / \mathrm{kg}$. Our results do not confirm his statement since, in 2012, between 2.8 and $3.8 \%$ of grains were contaminated at different spraying speeds, while the DON content in the grains was very low. FDK on the sprayed plots decreased by $76 \%$ in 2011 and by $74 \%$ one year later, which was similar to the findings of Mesterházy et al. (2011) ( $79 \%$ and $84 \%$, respectively).

The increase of the spraying speed from $5 \mathrm{~km} / \mathrm{h}$ to $8.5 \mathrm{~km} / \mathrm{h}$ and $12 \mathrm{~km} / \mathrm{h}$ resulted in a lower coverage value on the front and rear parts of a wheat head. This result is linked to a lower volume application rate at higher spraying speeds. At all three spraying speeds, the coverage of the rear part of a wheat head was better than the coverage of its front part. The effect of spraying speed was determined in 2011, when the application of the $5 \mathrm{~km} / \mathrm{h}$ spraying speed resulted in higher grain yield and thousand-grain weight in comparison with the other treatments. Moreover, lower FHB incidence occurred at the $5 \mathrm{~km} / \mathrm{h}$ and $8.5 \mathrm{~km} / \mathrm{h}$ spraying speeds. In both trial years, the lowest grain yield, hectolitre weight and thousand-grain weight occurred on the unsprayed control. The effect of spraying speed on the DON content in the grains was not significant. 


\section{References}

Blandino, M., Minelli, L., Reyneri, A. 2006. Strategies for the chemical control of Fusarium head blight: Effect on yield, alveographic parameters and deoxynivalenol contamination in winter wheat grain. Eur. J. Agron. 25:193-201.

Blandino, M., Haidukowski, M., Pascale, M., Plizzari, L., Scudellari, D., Reyneri, A. 2012. Integrated strategies for the control of Fusarium head blight and deoxynivalenol contamination in winter wheat. Field Crops Res. 133:139-149.

Commission Regulation (EC) No 856/2005 of 6 June 2005. Official J. European Union.

Derksen, R.C., Paul, P.A., Ozkan, H.E. 2012. Field evaluations of application techniques for fungicide spray deposition on wheat and artificial targets. Appl. Engineering in Agric. 28:325-331.

Eyal, Z., Scharen, A.L., Prescott, J.M., van Ginkel, M. 1987. The Septoria Diseases of Wheat: Concepts and Methods of Disease Management. CIMMYT. Mexico, D.F., Mexico, 52 pp.

Groth, J., Tamburic-Ilincic, L., Schaafsma, A., Brûlé-Babel, A., Hartl, L. 2011. FHB resistance of winter wheat from Canada and Europe estimated across multi-environments after inoculation with two deoxynivalenol producing Fusarium species source. Cereal Res. Commun. 39:189-199.

Halley, S., Pederson, J., McMullen, M., Lukach, J. 1999. Sprayer modifications for enhanced control of Fusarium head blight with fungicides. In: Proc. National Fusarium Head Blight Forum. Sioux Fall, SD, USA, pp. 51-52.

Hart, P., vanEe, G., Ledebuhr, R. Uniform fungicide trial collaborative study 2001 - Michigan State University. In: Proc. National Fusarium Head Blight Forum. Erlanger, KY, USA, pp. 54-58.

Homdork, S., Fehrmann, H., Beck, R. 2000. Effects of field application of tebuconazole on yield, yield components and the mycotoxin content of Fusarium-infected wheat grain. J. Phytopathol. 148:1-6.

Hooker, D.C., Spieser, H., Schaafsma, A.W. 2004. Effective application of fungicides on wheat heads: What's the best? In: Proc. $2^{\text {nd }}$ Int. Symp. on Fusarium Head Blight Incorporating the 8th European Fusarium Seminar. Orlando, FL, USA, p. 330.

Hooker, D.C., Spieser, H., Schaafsma, A.W. 2005. Effective application of fungicides on wheat heads: What's the best? In: Proc. National Fusarium Head Blight Forum. Milwaukee, WI, USA, p. 209.

Jones, R.K. 2000. Assessments of Fusarium head blight of wheat and barley in response to fungicide treatment. Plant Disease 84:1021-1030.

Knewitz, H., Koch, H. 2010. Was die neuen Düsen bringen (Characteristics of new nozzle types). DLG-Mitteilungen 3:68-71. (in German)

Lechoczki-Krsjak, S., Toth, B., Kotai, C., Martonosi, I., Farady, L., Kondrak, L., Szabo-Hever, A., Mesterházy, A. 2008. Chemical control of FHB in wheat with different nozzle types and fungicides. Cereal Res. Commun. 36:677-681.

McMullen, M., Halley, S., Pederson, J., Moos, J., Hofman, V., Panagrahi, S. 1999a. How spray nozzles, pressures, and gpa affect coverage and fungicide efficacy for Fusarium head blight control. Fargo, ND, USA. Phytopathol. 89:106.

McMullen, M., Halley, S., Pederson, J., Hofman, V., Moos, J., Panigrahi, S., Gu, D., Gregoire, T. 1999b. NDSU greenhouse studies: yield more tips for improved fungicide spraying for wheat/barley head scab control; Extension Report 56. Fargo, ND, USA, pp. 1-5.

McMullen, M., Lukach, J., McKay, K., Schatz, B. 2001. Wheat uniform fungicide and biocontrol trials. In: Proc. National Fusarium Head Blight Forum. Erlanger, KY, USA, pp. 67-69.

Mesterházy, Á., Bartók, T., Lamper, C. 2003. Influence of cultivar resistance, epidemic severity, and Fusarium species on the efficacy of fungicide control of Fusarium head blight in wheat and deoxynivalenol (DON) contamination of grain. Plant Disease 87:1107-1115.

Mesterházy, Á., Tóth, B., Varga, M., Bartók, T., Szabó-Hevér, Á., Farády, L., Lehoczki-Krsjak, S. 2011. Role of fungicides, application of nozzle types, and the resistance level of wheat varieties in the control of Fusarium head blight and deoxynivalenol. Toxins 3:1453-1483.

Miedaner, T. 2012. Mykotoksine in Weizen und Mais. Fusarien erfolgreich vorbeugen (Mycotoxins in Wheat and Maize. Efficient Fusarium control). DLG Verlag GmbH, Frankfurt am Main, Germany, 88 pp. (in German)

Miller, P.C.H., Lane, A.G., Wheeler, H.C. 2002. Optimising fungicide application according to crop canopy characteristics in wheat. Project Report No. 277, HGCA, London, UK. 
Parkin, C.S., Miller, P.C.H., Magan, N., Aldred, D., Gill, J., Orson, J.H. 2006. The deposition of fungicides on ears to control Fusarium ear blight and the mycotoxin contamination of grain. Aspects Appl. Biol. 77:445-452.

Ruden, B.E., Draper, M.A., Ruden, K.R. 2005. Sprayer nozzle configurations and effects on fungicide spray deposition on wheat heads. In: Proc. National Fusarium Head Blight Forum. Milwaukee, WI, USA, p. 230.

Ruden, B.E., Draper, M.A., Roden, R., Wittmeier, D.S., Thompson, S.M. 2007. Fungicide coverage of the wheat rachis, related fungicide movement and effective control of Fusarium head blight. Phytopathol. 97:164.

Vajs, S., Leskošek, G., Simončic, A., Lešnik, M. 2008. Comparison of effectiveness of standard and drift-reducing nozzles for control of some winter wheat diseases. J. Plant Diseases and Protection 115:23-31. 